\title{
El lèxic botànic en el Libre de Caça i els termes corresponents en altres tractats romànics
}

\author{
The medieval botanical lexicon in some falconry works in romance \\ languages
}

\author{
antoni Mas i Miralles \\ antoni.mas@ua.es \\ ORCID: 0000-0003-0003-7594
}

Universitat d'Alacant

\begin{abstract}
Resum: Durant l'edat mitjana, els tractats de falconeria es dedicaven, entre altres assumptes, a descriure els símptomes i malalties que patien les aus, i oferien com a cures pal liatives diferents remeis terapèutics a partir de les plantes medicinals. Aquest treball presenta un inventari de termes botànics que registrem en una obra del segle xv, el Llibre de Caça, a més dels vocables corresponents que hem trobat en quatre obres de falconeria medieval de tantes altres llengües romàniques: portuguès, castellà, francès i italià. De cada terme exposem quines propietats curatives tenien, el nom científic de la planta de què procedeix, l'etimologia del mot, juntament amb l'ètim estàndard actual. Finalment presentem una possible classificació dels vocables segons l'etimologia i les llengües.
\end{abstract}

Paraules clau: lexicologia, botànica, llengües romàniques, falconeria.

\begin{abstract}
In the Middle Ages, the falconry treaties focused on, among other topics, describing the symptoms and diseases of the birds, and offered as pallative care different therapeutic remedies from medicinal plants. This article presents a list of botanical terms used in five Medieval falconry works in five Romance languages: Portuguese, Spanish, Catalan, French and Italian. From the Latin scientific term, consisting of the genus and species, we propose its etymology together with the current term. Finally, we present a posible classification and distribution by words and languages.
\end{abstract}

Keywords: lexicology, botany, romance languages, falconry. 
Antoni Mas i Miralles. El lèxic botànic en el Libre de Caça i els termes corresponents en altres tractats romànics

\section{Introducció}

\subsection{Els llibres de falconeria}

Si al principi el llatí representava la llengua en exclusiva dels registres més formals, és a partir de la baixa edat mitjana quan les llengües vulgars comencen a disputar-li aquest predomini lingüístic. Així, durant l'esmentada època, aquestes llengües inicien el desplaçament del llatí en la producció d'un significatiu nombre d'obres científiques i tècniques. Tot açò suposa, per una part, un procés de traducció d'obres de llatí, sense oblidar tampoc les traduccions de l'àrab o de l'hebreu i, per una altra part, l'elaboració a partir de còpies o de compilacions d'obres ja existents (Santoyo, 2004). En la majoria dels casos, aquests canvis en la selecció lingüística comencen per textos fonamentalment de caràcter mèdic (tant dirigits a persones com també a animals) juntament amb obres filosòfiques. Tot açò conforma el que Cifuentes (2006) arriba a denominar com a procés de vernacularització.

Aquest període coincideix amb l'aparició d'un destacat nombre d'obres medievals dedicades a l'art de la falconeria. Els tractats medievals de falconeria contenien unes característiques especials per la seua producció i pels seus destinataris, que, com bé sabem, eren els reis i els nobles. D'altra banda, aquestes obres recopilaven tot el coneixement existent fins al moment sobre la cura $i$ l'ensinistrament que necessitaven les aus de caça, ja que als falconers -els encarregats de vigilar tan apreuades aus- havien de tenir amplis coneixements tècnics i mèdics i, per descomptat, també excel lents destreses manuals.

En la majoria de casos, els autors dels llibres de falconeria es dediquen a traduir del llatí a les llengües romàniques, i d'unes llengües romàniques a unes altres, i també a compilar la informació disponible en altres manuscrits. Aquests textos tècnics ofereixen fonaments científics tant des del punt de vista ornitològic com cinegètic. Generalment, comencen sempre per una classificació dels diferents tipus de falcons (morfologia, estructura i plomes d'aquestes aus), per a passar a continuació a la informació veterinària que comprèn els diferents aspectes higiènics i terapèutics necessaris per a la seua acurada vigilància. Des d'aquesta perspectiva, doncs, les obres de falconeria arrepleguen una important mostra de vocabulari específic de diferents camps semàntics. Trobem noms de diferents espècies d'aus de rampinya, d'animals relacionats amb la caça, termes referits a la seua anatomia i al seu plomatge, diferents utensilis d'ús comú entre els falconers, les possibles malalties $\mathrm{i}$ accidents que podien patir, amb un ampli ventall referit als símptomes i diagnòstics possibles, a més d'un extens llistat de remeis i recomanacions a tenir en compte pels seus cuidadors; i no podem oblidar el nom dels diferents instruments que la medicina de llavors posava a l'abast dels cuidadors d'aquests animals. Entre aquests remeis s'inclö̈en les dietes i consells per a una alimentació correcta i, fonamentalment, per a un tractament terapèutic encertat. Aquestes receptes comprenien, primordialment, els productes naturals que s'extreien de les plantes o dels seus fruits.

Com ja hem exposat anteriorment, als falconers se'ls exigien vasts coneixements tècnics, entre els quals ens interessa destacar ara els que feien referència a la botànica, és a dir, a més de les seues 
nocions veterinàries per a poder encertar en els diferents diagnòstics i prescripcions de les malalties, era necessari també posseir amplis coneixements de les qualitats terapèutiques de les plantes. Per açò, el control dels diferents gèneres i espècies de les plantes era condició sine qua non per a aquests cuidadors. O dit d'una altra manera, el coneixement de les plantes facilitava el restabliment de la salut de tan valuosos animals. D'ací l'interès del falconer de controlar les plantes que havia d'utilitzar per a cada remei.

\subsection{Els objectius}

En aquest treball ens proposem estudiar el lèxic botànic que registrem en una obra del segle xv, el Llibre de Caça, a més dels termes corresponents que hem trobat en quatre obres de falconeria medievals de tantes altres llengües romàniques: portuguès, castellà, francès i italià. Cal ressaltar, en primer lloc, que aquest camp semàntic de la botànica ofereix unes peculiars característiques per a qualsevol anàlisi lexicològica, ja que ens permet observar l'evolució del vocabulari botànic a partir de les diferents etimologies o termes populars recollits per aquests textos, quan molts d'aquests tractats eren deutors de traduccions del llatí o convivien encara en ple contacte amb aquesta llengua, almenys en aquests registres de caràcter tècnic i científic.

Els objectius d'aquest treball són els següents:

a) Oferir un inventari de les plantes que registrem en un text del segle xv, Llibre de Caça.

b) Analitzar cada mot del text català, i, quan siga possible, anotar els mots corresponents que trobem en altres quatre tractats de falconeria medieval d'altres llengües romàniques: portuguès, castellà, francès i italià.

c) Identificar el nom científic de cada planta, per a conèixer també si el nom de la planta deriva del gènere, de l'espècie o d'una forma popular.

d) Buscar l'etimologia de cada terme.

e) Fer diferents propostes de classificació d'aquest vocabulari arreplegat per a conèixer, d'una banda, com influeix l'etimologia de cada ètim entre el llatí i l'àrab i, d'altra banda, si el nom deriva del gènere, de l'espècie o d'una altra forma popular.

\subsection{Les fonts}

Com ja hem avançat, el nostre treball es basa en la recopilació del vocabulari botànic recollit en el Llibre de Caça, un tractat escrit en català, anònim i conservat en un manuscrit (ms. 505 de la Biblioteca Històrica de la Universitat de València) de finals del segle XV o dels primers anys del XVI. Probablement és còpia d'un arquetip, el text original del qual és segurament de finals del segle XIV o de principis del xv.. En quasi 100 folis i 141 capítols aquest tractat de falconeria fa una detallada 
Antoni Mas i Miralles. El lèxic botànic en el Libre de Caça i els termes corresponents en altres

tractats romànics

descripció sobre ornitologia, cinegètica i terapèutica. És un testimoniatge fonamental per la seua extensió i homogeneïtat de la redacció, per la precisió del contingut i per les seues particularitats lingüístiques. Aquest manuscrit actualment està editat (Garcia et al 2013).

L'anàlisi d'aquest recull lèxic s'ha pogut acompanyar amb els vocables que trobem en les mateixes fórmules terapèutiques en quatre textos medievals de tantes altres llengües romàniques. Aquests textos són els següents:

a) El Llivro de falcoaria, escrit en portuguès entre 1345 i 1386 per Pero Menino, falconer del rei Fernando I de Portugal. La importància d'aquesta obra radica per a alguns estudiosos en la seua originalitat, ja que inclou il lustracions molt explicatives. A més, descriu alguns capítols amb tot tipus de detall, fet que podríem qualificar com a petites intervencions quirúrgiques. Es conserva en quatre manuscrits del segle XV $i$ va tenir una gran influència en els textos de falconeria peninsular, ja que Pero López d'Ayala i Gonzalo Rodríguez Escobar el van tenir com a model, i va ser copiat també per altres obres escrites en català.

b) El Libro de la Caça de las aves fou redactat en castellà a finals del segle XIV pel canceller Pero López d'Ayala, mentre es trobava presoner a Óvidos, després de la derrota d'Albujarrota en 1385. El seu contingut es distribueix en tres parts: la primera dedicada a la descripció de les aus i a la seua distribució geogràfica; la segona, a l'entrenament, i, en la tercera, arreplega tota la informació mèdico-farmacèutica. Té com a còpia bàsica l'obra portuguesa apuntada en l'apartat anterior. Per a molts es tracta d'una traducció literal, però sembla ser que en algunes ocasions beu d'altres fonts. La traducció i ampliació feta per aquest canceller va ser bastant coneguda si tenim en compte que es conserva en trenta manuscrits i edicions impreses, a més de servir de model per a autors com Juan de Sahagún i Juan de Vallés, entre d’altres.

c) Trataire de faulconnerie, obra anònima escrita en francès a mitjan segle Xv. Aquest llibre forma part del manuscrit fr. 2004 que es troba en la Biblioteca Nacional de França. El manuscrit conté un pròleg i tres tractats: Lliure de Faulconnerie, Medecines pour faulcons i, finalment, el nostre tractat, triat per a dur a terme aquest treball. El Trataire consta de 6 capítols i, com els altres textos, és una compilació de la informació arreplegada a partir de 3 obres, segons l'opinió de Lagae (2005).

d) Pratica de citreria breu de Maties Mercader, escrit en italià el 1475. Aquest ardiaca de la catedral de València es va desplaçar més tard a la cort napolitana, on va redactar aquesta obra dedicada al rei don Fernando de Nàpols (Cifuentes 2006). Procedeix d'una família que va exercir certa influència en la vida cultural de València del segle XV gràcies a la seua extensa biblioteca, encara que no tots coincideixen amb aquesta apreciació (Wittlin 1998). 
Antoni Mas i Miralles. El lèxic botànic en el Libre de Caça i els termes corresponents en altres

tractats romànics

\subsection{La metodologia}

Com ja sabem, existia en aquest tipus d'obres de falconeria medieval, i suposem que també en altres gèneres, la tradició de traduir i copiar uns textos d'altres, de tal manera que descobrim una xarxa de còpies i traduccions d'unes llengües a unes altres. Aquesta és la premissa que ens permet comprovar la correspondència $i$ alhora l'equivalència semàntica d'un determinat ètim lèxic d'una llengua a una altra. Així, en moltes ocasions és l'etimologia de la paraula la que ens corrobora la correspondència lèxica, però en altres casos és la reproducció de la fórmula proposada per a la curació d'una malaltia, que en la majoria de les vegades és idèntica d'un text a l'altre, el recurs eficaç que ens revela el terme recíproc, en el nostre cas: el nom de les plantes.

Comprovem a continuació com per a desparasitar un falcó el remei proposat pels textos castellà, català, francès i italià són quasi idèntics. En tots trobem l'ús de l'estafisagria o fabara\%. La pols d'aquesta planta es bullia en aigua i, quan estava tèbia, es banyava l'animal amb un drap de lli net, després es deixava a assecar durant mitja hora al sol fins que estiguera completament sec. D'aquesta manera sabem que fabarra\%, fabara\%, strafisagria i desetafizacre utilitzats en les respectives obres són variants en cada llengua de la mateixa planta, la Delphinium staphisagria. Vegem com els diferents autors repeteixen, més o menys, la mateixa estructura i les paraules més significatives, que deixem en negreta:

\section{- Pero López d'Ayala (Libro de la Caça de las aves)}

e un quarto de onça de fabarraz molido, e átalo en un trapo, e pon en un baçín o en una gamella pequeña del agua tibia e algún vino blanco, quanto el quarto, e faz salir toda la fuerça de los polvos de la pimienta e fabarraz que tienes en el trapo en el agua. E después pon un paño de lino en el baçín [...]. E desque bien lo ovieres así vañado e requerido, enbuélvelo en un paño de lino blanco e linpio, e esté así encamisado una pieça ençima de un hazeruelo, e después desenbuélvelo e tómalo en la mano e tenlo al sol fasta que se vaya enxugando (cap. IX).

\section{- Anònim (Llibre de caça)}

preneu quatre grans de fabaraz e mondau-los e esclafau-los, e lligau-los ab un fil dins un drapet de lli prim. E, fet açò, preneu tanta aygua calenta com mija nou en una scudelleta, e posau allí lo dit drapet ab los dits grans del fabaraz, e spremeu-los allí bé, e tornarà la dita aigua blanca com si fos llet. E, fet açò, preneu lo dit ocell destrament e, depuix, mullau una plometa o un bastonet en la dita aygua, e posau-li'n una gota o dos en cada ventana, que li entre dins lo nas, e que sia fet molt destrament; e guardats-vos no li'n cayga en la boca ni en los ulls, si no, segar-lo-iets. E, fet açò, posau lo ocell al sol e allí dexau obrar la dita medecina [...]. E, fet tot açò, soltau-lo al puny, e meteu-lo al sol en una barra e stiga-y mija ora e, depuix, tornau-lo a pendre al puny e ruxau-li bé la cara ab aygua clara. E, quant la y hajats axí ruxada, tornats-lo al sol e stiga allí tro que sia exut. [46r-8/28]. 
Antoni Mas i Miralles. El lèxic botànic en el Libre de Caça i els termes corresponents en altres

tractats romànics

\section{- M. Mercader (Pratica de citreria breve)}

Se questo non basta pigliarite la herba che si chiama strafisagria mondirtenen cinque o sei grana: poneritili di poit dentro uno panno de lino necto, e che sia usato, purche non sia stato panno de donna, e maccate un poco dicti grani de strafisagria dentro dicto panno, lo ponerite dentre una scutella ove sia un poco de late, e se non un poco de acqua tepida e exprimerite bene dicta strafisagria fin tanto ne sia andato de quela substantia in l'acqua o lacte. Da poi, lo farite tepido e ponerite ad cascuna ventana doe o tre gotte. Ponerite al sole. Purgara et se per ventura lo falcone se angustiasse troppo che non lo possesse patere, li rusciarite la facçia como de sopra e dicto con aqua tepida (p. 12).

\section{- L'Anonyme de Paris (VI. 15)}

[...] prenez ung pou desetafizacre et le faites bien mouder puiz prenez ung pot de terre tout noeuf, tenant la montance d'une quarte ou plus, puiz l'emplisiez d'eaue bien clere et le mettez boullir avec la pouldre tant qu'elle appetisse a moitié, aprez le coulez en ung bachin parmy ung linge drap. Et quant elle sera tiede si enlavez vostre oiseau en jeun, qu'il n'ait riens dedens la gorge et aprez le mettez en l'ombre l'espace de demye heure et le mettez au soleil tant qu'il soit bien espluquiet et sec que jamais. I cellui plus n'aura poulx, ne il ne changera son dit plumaje de couleur. (Lagae 2005: 73).

\section{Anàlisi lèxica}

Iniciem l'anàlisi lèxica de l'inventari botànic del Llibre de Caça amb l'exposició de cada terme, posem entre parèntesi si trobem variants, $i$, en els casos que hem considerat convenient, també reproduïm el fragment on registrem el vocable. Incloem en cada mot el nom científic, format pel gènere $\mathrm{i}$ l'espècie de cada planta -d'acord amb la denominació binomial de Linnaeus-; quan és possible, comentem les propietats generals de cada planta i en la fórmula terapèutica en què apareixen. A continuació, afegim els vocables corresponents que trobem en cada tractat de falconeria, encara que no sempre registrem les formes equivalents; aportem l'etimologia del mot estudiat, i, finalment, facilitem el referent actual estàndard en la respectiva llengua.

acèver. D'aquesta planta, Aloe vera, s'aconseguia un suc molt amargós i s'emprava en la majoria de fórmules farmacològiques, ja que servia tant per a aconseguir olis com diversos ungüents; també apareix en l'elaboració de píndoles per a l'aigua vidriada, a més de formar part de moltes fórmules per al purgament d'animals. Només el francès segueix l'etimologia llatina alone epatif 'aloes hépatique', mentre que la resta de llengües adopten l'etimologia àrab sabir (DCVB, s.v. àloe) o de sibar (DECat s.v. sèver) a partir de la qual obtenim en portuguès la paraula acevar $(9,25)^{1}$ 'aloé'; en

1 Anotem la página on apareix el mot d'acord amb l'edició esmentada de Rodrigues (1931). 
castellà tenim acíbar (c. XI), ${ }^{2}$ el 'áloe' o també 'acíbar'; en català trobem sèver (32r-14/16) 'acèver' o 'àloe', i, finalment, el text italià utilitza el terme acevar (7), 'aloe'. Com podem comprovar, malgrat l'ús d'arabismes en època medieval, les llengües romàniques, a excepció del francès, s'han decantat actualment per l'ús del terme que prové del llatí.

àlber. Arbre de la família de les salicínies: Populus alba. Les branques d'aquest arbre eren idònies per a fer barres on descansaven els animals. Tenim l'àlber (los puxau posar una barra, que sia de sàlser o de àlber, 6r-28) i també la variant àlber verd (Si volets bona barra per a tenir lo vostre falcó ho ocell, en especial en estiu, fets-la fer de àlber vert, 14r-5). Sobre l'etimologia, tot fa pensar que prové del llatí ALBĂRus (DCVB i DECat s.v. àlber).

alfalç (alfals). Es tracta de la planta lleguminosa Medicago sativa. Només en tenim testimoni en el text català (o dins lo alfalç, enperò no dexeu erba nenguna dins [1]o cevador segau-la prop terra, 93v). De la procedència aràbiga del mot, alfașfașa, no tenim cap dubte (DECat s.v. alfals).

almàstech. Planta de l'espècie Chondrilla juncea. Amb aquesta planta s'aconseguia una resina amb la qual s'elaborava un ungüent que tenia múltiples usos entre els falconers. El terme utilitzat en els textos prové de l'etimologia llatina MASTIX juntament amb l'article àrab mastaka $\mathrm{O}$ almastika (DCVB s.v. màstic i DA s.v. almáciga), i que ha derivat a les formes mastiz i també almacega $(4,5)$ 'almecegueira' en portuguès, almástiga (c.XXVIII) 'almáciga' en castellà, almàstec o també màstec (30v-2, 34r-5, 74r10, 91r-12) en català i mastice i almecega en italià. En època medieval també era anomenat resina del llentiscle (Gil 1999: 122).

alosna. És la planta Artemisia absinthium que servia, generalment, per a estroncar les ferides, però també per a un important nombre de malalties, com el tròpic, 'la hidropesia', o l'inflament del ventre. Aquesta espècie rep en àrab el nom d'aluxna, ètim pròxim a la paraula llatina ALOXĨNUM (DCVB s.v. alosna). L'aparició de l'article àrab al- en algunes formes ens confirma la procedència etimològica del mot. Malgrat açò, segurament algunes llengües seguiran l'etimologia àrab, ja que trobem la forma alosna homònima en els tractats de falconeria, en portuguès alosna (4) 'losna', en castellà 'alosna' (c.XXXI), en català i en italià també alosna $(81 \mathrm{v}-22,82 \mathrm{v}-13)$, mentre que el francès arreplega aloine 'aluine'. De la mateixa planta registrem el nom derivat de la forma llatina absinthüum. Per això trobem en el text castellà el terme ansenxo (c.XLVII) 'ajenjo' ${ }^{5}$ i assencio o nassèntio en el tractat italià 'assènzio', que és la mateixa veu derivada que ha produït en l'actualitat les paraules 'asente' del portuguès, 'absenta' en català i 'absinthe' en francès. Cal assenyalar que els autors són

2 Posem en xifres romanes el capítol on trobem aquest mot en l'edició de Delgado (2006).

3 Entre parèntesi, posem el número de la pàgina amb la indicació de recto o versus, i separat per un guionet la línia en què apareix el mot. Seguim l'edició d'aquest manuscrit publicat per Garcia et. al. (2013).

4 Marquem la pàgina on apareix el terme, segons el manuscrit descrit de M. Mercader.

5 Gil creu que aquesta forma deriva del mot incienso (1999: 129).

SCRIPTA, Revista internacional de literatura i cultura medieval i moderna, núm. 12/ desembre 2018/pp. 198-219 ISSN: 2340 - 4841 doi:10.7203/SCRIPTA.12.13393 
Antoni Mas i Miralles. El lèxic botànic en el Libre de Caça i els termes corresponents en altres

tractats romànics

conscients que es tracta d'una planta equivalent, i per açò el text castellà comenta "e toma otro día el alosna que es el asenxo amargo" (c.XXXI) o el text en català que també remarca l'equivalència "preneu alosna, en altra manera apellat donzell" (81v-22/23).

alquena. Arrels de la planta Lawsonia inermis, que, reduïdes a polsim i dissoltes amb aigua, s'empraven com a cosmètic, i principalment per tenyir els cabells i les celles. Els falconers utilitzaven aquest tint per a canviar de color les plomes de l'animal. Només es recull a l'obra catalana, alquena (81v-22, 82v-13) de l'àrab al-ḥanna segons el DCVB (s.v. alquena) o de binnâ' segons el DECat (s.v. alquena).

api. El conegut Apium graveolens s'utilitzava per al tractament del mal de pedra. Apareix solament en el text català amb la forma api (66r-14), a partir del nom del gènere. El mot procedeix de la forma llatina apium (DCVB i DECat s.v. api).

arzolla. És la Centaurea solstitialis. Les propietats d'aquesta planta eren aconsellades per a l'elaboració d'ungüents i emplastres que servien per a qualsevol trencament que poguera patir l'animal. En el text català trobem la paraula arzolla $(73 \mathrm{v}-33)$ 'blanquiella', l'etimologia de la qual prové de l'àrab alloza (DA, s.v. arzolla). Vegeu també sueldaraca.

burcalastorit. La Capsella bursa-pastoris és la planta que servia per a tractar les ferides o el trencament que poguera patir l'au. Era coneguda pel nom de l'espècie, així registrem l'ètim bruça pastoril (63) 'borsa de pastor' en el tractat portugués, bursa pastoris (cXXX) 'zurrón de pastor' en el castellà, i burcalastorit 'sarronet de pastor' en el text català, mentre que l'italià tenim virga pastoris 'borsapastoris'.

cagamusa. Planta de la família de les euforbiàcies, Euphorbia lathyris. Si els falconers volien mantenir les seues aus sanes en època de muda, utilitzaven sempre aquesta planta. En les obres portuguesa i castellana trobem tartego (17) i tártago (c.XX), respectivament. En canvi, a partir de l'altre nom que rebia del greco-llatí CATAPOTIA (DECat, s.v. cagamuixa), obtenim en català cataprusa (21v-8), que correspon a les formes actuals 'cataprusa' o 'cagamoixa', i en francès al terme cataponya, 'catapuce'.

camamirla. És la Matricaria Chamomilla amb la qual s'elaborava un ungüent per al tractament dels colps i ferides. El nom de l'espècie produeix el terme camamirla (70v-29, 71r-19, 71 r-20) 'camomil la' que trobem en el text català i camomilla, en l'italià i que procedeix del llatí (DCVB s.v. camamil la) i procedent del grec 'pomera de terra' (DECat s.v. camamilla).

canella. Aquesta planta, Cinnamomum verum, era utilitzada en múltiples fórmules, la majoria per a tractaments estomacals. Gaudia d'una gran estima entre els falconers, i segurament per açò la trobem referenciada en totes les obres. Així el text portugués parla de la canela (4), igual que el text castellà on veiem també canela (c.XXXIII), en català tenim canella (30r-31), també flor de canella (30v1), i en italià cannèlla, del llatí cannelda, derivat de canya (DECat s.v. canya). Com veiem aquestes quatre llengües utilitzen la forma popular, mentre que en el text francés utilitza la forma synamon 'cannelle', derivada del nom del gènere. 
Antoni Mas i Miralles. El lèxic botànic en el Libre de Caça i els termes corresponents en altres

tractats romànics

canyafístola (caxafístola). Planta de la família de les lleguminoses, Casiae fistŭla, que s'usava per a provocar el vòmit a causa de les seues propietats laxants. En aquest cas tant el gènere com l'espècie s'han utilitzat per a crear la paraula canyafístola (25r-3, 25v-5) 'canyafístula', que arrepleguem només en el tractat català i que procedeix del llatí (DCVB s.v. canyafistula) segurament per influència de la forma castellana.

clavell de girofle. Es tracata de la Syzygium aromaticum. D'aquests claus d'espècia utilitzats com a condiment també s'extrau una essència amb ús farmacològic. En el text portugués trobem cravos (3) 'cravinho' i també girofos (58), en el castellà tenim clavos de girofle (c.XXXIII), en català veiem claus de girofle (30r-31), així mateix en francès tenim cloux de giroflé, mentre que en italià anotem la forma gariofali. La forma girofle prové del llatí GARIOFULU (DECat, s.v. girofle).

consolda. Planta de la família de les borraginàcies, Symphytum officinale. S’utilitzava sempre per al tractament de colps o trencaments d'ossos. Apareix en tots els textos. La registrem en portuguès amb el nom de solda (4), en el castellà suelda (c.XXIV) 'consuelda', consolda (81r-26, 81r-28, 82r-15, etc.) en català, consoude en el text francés i l'italià reprodueix consolida. Tots aquests termes equivalents procedeixen de l'ètim llatí consolida (DCVB, s.v. consolda), segons Coromines com un derivat del verb consolidar (DECat s.v. sou). Volem recordar que en el text castellà apareix com a alternativa a la suelda raca, i que en el català ofereix la possibilitat d'utilitzar amb les mateixes propietats de l'arzolla.

crespinell. Planta crassulàcia de diferents espècies del gènere Sedum acre. Utilitzada en els tractaments de qualsevol inflor. El text català reprodueix el nom comú de crespinell (36r-23, 37v-4, 37v-9, etc.), el francès orpin i l'italià tenim morella vora 'borracina'. Tornem a comprovar que en moltes ocasions els noms de les plantes més populars no seguien l'etimologia derivada ni del gènere ni de l'espècie, ja que aquestes denominacions científiques són posteriors als tractats medievals. El DECat (s.v. cresp) en parla sense dir-ne la procedència.

donzell. Segurament es refereix a Artemisia absinthium. El donzell (29r-9, 34v-24, 59r-22etc.) el trobem en el text català, i deriva de la forma llatina CARDUnCELLus (DCVB s.v. donzell). El DECat (s.v. donzell) arreplega la forma herba d'onzell, que possiblement siga el mateix que el doncel castellà, i correspon a 'alòsanus', que és 'àloe agre'. A més Coromines la relaciona amb el mot castellà ajenjo. En canvi en francès ens apareix la forma armoise, segurament un derivat de la forma del gènere artemisia. En aquest cas hauríem de plantejar-nos si ens estem referint al mateix gènere de l'Artemisia, però en aquest cas per a descriure l'espècie arborescens (Artemisia arborescens) De moment, no tenim suficient criteri per a afirmar que el codesso, que trobem en el text portugués, pertanya també a aquesta classe de plantes; sí sabem segur que amb el nom de codesso denominem diverses espècies que hom coneix com a cytius. Vegeu més amunt alosna.

ensens. Aquesta planta, Boswellia sacra Flueckiger, apareix en tots els textos estudiats. L'etimologia INCENSU del llatí, i que Coromines la fa derivar de la forma verbal encendre (DECat s.v. encendre) és la mateixa en les cinc llengües, ja que trobem incensso (4) en portuguès, ençienso (c.XLV) en castellà, ensens $(30 \mathrm{v}-2)$ 'encens' en català, encens en francès i, finalment, incènso en italià 
Antoni Mas i Miralles. El lèxic botànic en el Libre de Caça i els termes corresponents en altres

tractats romànics

espic. Segurament aquest nom científic correspon també a Lavandula latifolia. A partir de la forma llatina sPICCA (DCVB s.v. espigol), nom popular de la planta, obtenim en portugués espique (4), espic i espique (c.IX) 'lavándula', 'espígol' en el castellà, en català tenim espic (47r-14) 'espígol', i en italià trobem spica 'espígol'.

exonca. Segurament ens refereix a la Conium maculatum. És clar que es tracta d'un altre castellanisme que ha copiat de l'obra de López d'Ayala (i pren una yerva que dizen eixonca i faç d'ella pols ben sotil i una mica de cardenillo [Cap. XXIII]) Aquesta planta es relaciona amb les fórmules que cercaven remeis per al mal de la fístula. En el text portugués trobem la referència a la cixuta 'cicuta' del llatí CICUTA, en canvi tant en castellà com en català, possiblement perquè el segon copia al primer, trobem les formes eixonca 'cicuta' i exonca (84v-25) 'cicuta', respectivament, noms populars de la planta.

fabaraç (fabaraz). Aquesta era una de les plantes, el Delphinium staphisagria, més conegudes i usades pels falconers. Entre els seus múltiples usos, era recomanada per a l'extracció de l'aigua i el tractament contra els polls. En aquesta planta podem diferenciar dos noms. En primer lloc, a partir del terme grec tenim el nom de l'espècie staphisagrăa en els textos francés i italià amb les paraules estafizacre 'staphisaigre' i strafisagria 'stafisagria', respectivament. En segon lloc, les llengües ibèriques segueixen l'etimologia de l'ètim àrab ḥább ar rás (DECat s.v. fabarràs) amb el qual s’ha format en portuguès la paraula paparaz (15) 'paparraz', 'estafisàgria', el castellà fabarraz (c.XVII) 'abarraz', 'estafisagria', i en català tenim fabaraz (34v-29, 34v-33, 44r-20, etc.) 'estafisàgria'. Com hem pogut comprovar, encara que aquestes llengües utilitzaven arabismes en l'època medieval, en els diccionaris normatius han optat finalment per la forma derivada del llatí.

falsia. Planta polipodiàcia de l'espècie Adianthum capillus-Veneris. D'aquesta planta s'extreia un suc per a tractar les infeccions dels ulls o també per a tractar les pedres. En el text castellà trobem el terme culantro 'culantrillo', que López d'Ayala el relaciona amb el nom de l'espècie en llatí ("toma la yerva que dizen capili veneris, otros la llaman culantro", c. XXII); en català s'utilitza el terme comú de falsia, que correspon també a la 'falsia' (21r-18) o a el 'coriandre'; el text italià arreplega la paraula cogliandro, el 'capelvenere'. Segons el DECat (s.v. celiandre) sembla ser que aquestes formes deriven de la forma llatina CERIANDRum. El nom popular en castellà és culantrillo del pozo.

fenoll. És la Foeniculum vulgare. Trobem aquesta coneguda planta en la majoria de tractaments relacionats amb l'estómac i amb els problemes intestinals. Totes les llengües parteixen del gènere de la planta, nom que procedeix del llatí (DCVB s.v. fonoll). Així registrem funcho (4) en el text portugués, finojo (c.XI) 'fenoll' en castellà, finojo (77r-23, 78v-34) en català, fenoul, 'fenouil' en francès i, finalment, fenochio 'finoccio' en italià.

fetge. La planta Hepatica nobilis, coneguda també amb el nom de llengua de bou, és utilitzada per a les malalties del càncer. Solament apareix en el text català sota el nom popular de la planta, fetge 'fetgera' (57r-16, 57r-31) i que prové del llatí FÉTicu (DECat s.v. fetge). 
Antoni Mas i Miralles. El lèxic botànic en el Libre de Caça i els termes corresponents en altres

tractats romànics

genciana. Planta gencianàcia de diferents espècies, i principalment la Gentiana lutea. A diferència de les altres espècies que tenen la flor de color blau, aquesta la té de color taronja. Era utilitzada per als tractaments de les fístules. En el text català trobem aquesta planta amb el nom de genciana (50v-12, 84v-27), derivada del gènere,

gingebre. Planta zingiberàcia de l'espècie Zingiber officinale, originària de l'Índia i conreada per aprofitar el seu rizoma gros i olorós, emprat com a condiment. A partir del gènere de la planta, trobem en els textos català $\mathrm{i}$ italià els termes jengibre 'gingebre' $(29 \mathrm{v}-19,31 \mathrm{r}-21,31 \mathrm{v}-25)$ i żinz̧ivero 'zènzero', respectivament. Aquest ètim també prové del llatí (DCVB s.v. gingebre).

giripriga (giripligua). L'Aloe perryi Bark és l'acèver sucotrí, segons Coromines perquè és produïa a l'illa aràbiga de Soqotra. També es refereix a l'àloe sucotri, que en època medieval es coneixia com a giripigra, que després formà, segurament per metàtesi, els termes giripriga i també giripliga, hui giripiga. (45v-8, 51v-18, 51v-19, etc.). El DECat apunta que és tracta d'«una certa droga medicinal ingredient de pocions i begudes» (s.v. jerarquia). El text català aporta el terme sèver sucotrí (30r-4) i el text italià gerapriga. L'equivalent en castellà és 'jerapliega', del llatí medieval GERAPIGRA, procedent del

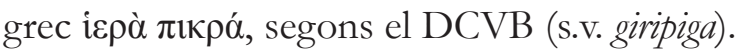

herba cuquera. Es tracta de la Santolina chamaecyparissus o de la Sanguisorba minor. Nom de diferents espècies a les quals se'ls atribueixen propietats vermífugues. El nom popular que trobem en els textos ibèrics, ho confirmen. Així en portuguès tenim erva lonbrigueira (4), que és la yerba lombriguera (c.XXI) 'abrótano' en castellà i l'herba cuquera (87 v-26) 'espernallac' en català.

hermotàtil. Es tracta de la Colcbicum autumnale. L'arrel d'aquesta planta s'utilitzava en farmàcia especialment com a purgant i s'ha d'anar alerta perquè el còlquic és un verí potentíssim. El nom d'aquesta planta apareix només en els textos català i italià. En el primer trobem hermotàtil 'lliri' o 'hermodàctil', i ermodattoli (60v-13) en el segon. En aquest cas el nom llatí d'aquesta planta

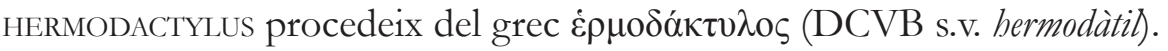

jolivert. Correspon a la Petroselinum crispum. Aquesta coneguda planta apareix en diferents fórmules, ja que s'usava d'igual manera tant per a guarir ferides com per a malalties, com el mal de pedra, la litiasis, etc. El text castellà arreplega el terme perexil (c.XXII) 'perejil' i en el francès trobem persin 'persil', derivats els dos del gènere de la planta, mentre que el text català opta per una altra etimologia per a construir jolivert (42r-19, 42r-22, 65v-22, etc.) a partir de LOLIU VIRIDE (DCVB, s.v. julivert).

junc boval. Es pot referir tant a la planta Juncus communis o la Juncus effusus. Amb les branques dels juncs es feien gàbies per als ocells, només l'enregistrem en el text català ( $E$ deveu-los tenir enramats de dures de rames e de junchs, de aquests bovals, 6v-7). L'etimologia del mot procedeix del llatí IŬNCU.(DCVB s.v. jonc). 
Antoni Mas i Miralles. El lèxic botànic en el Libre de Caça i els termes corresponents en altres tractats romànics

llentiscle. Amb el suc d'aquesta planta, Pistacia lentiscus, es tractaven les malalties relacionades amb els ulls. D'aquesta s'aconseguia també un tipus de resina per a obtenir almàciga, com ja hem apuntat anteriorment. Amb el nom de l'espècie tenim el terme llentiscle (49r-12) 'màstic' en català i lentisco ‘lentischio’ en italià. Procedeix del llatí (DCVB s.v. llentiscle)

llimó. Aquest conegut cítric, Citrus limonum, apareix en els textos català i italià com limó (50r-11) 'llimó' i limone o limoncelo, respectivament, derivat del nom de l'espècie.

manruvio. Planta labiada de l'espècie Marrubium vulgare, també coneguda com Ballota birsuta Benth. Només el text català registra aquesta planta amb el nom de manrubio (91v-19) 'malrubí', nom format a partir del gènere.

margarida. Es tracta de la planta Cytinus hypocistis. S'utilitzava també per als remeis de trencadures diverses de l'animal. En català margarita (preneu de una erba que a nom margarita e picau-la e

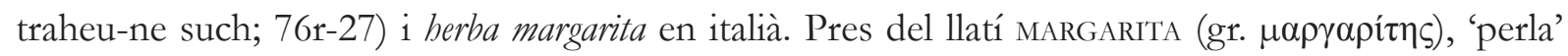
(DCVB s.v. margarida).

menudina. Es refereix a l'herba menuda, de l'espècie Artemisia camphorata, de fulles puntejades, verdes, amb molta olor de càmfora. Aquesta planta s'utilitzava en la fórmula amb què preparaven els emplastres per als trencaments de qualsevol membre de l'animal. El text castellà de López d'Ayala recull menudilla (y la simente de la yerva menudilla que llaman suelda menor [Cap. XXVIII]), forma que, segurament, el copista català copia. En canvi, hem d'assenyalar que aquest mot no el recull ni el DRAE ni tampoc el DIEC2. La identifiquem com la maminha (46) del text portugués 'herba madroa', i amb la menudilla del text castellà 'artemisa', també amb la menudina (72v-30) que trobem en el català 'herba quina' i l'herba minuta 'erba margarida' que veiem en l'italià. El text castellà la relaciona amb la suelda menor (e la simente de la yerva menudilla que llaman suelda menor, c. XXVIII), també coneguda com a consuelda.

mielsana. Segurament es refereix a la Prunella grandiflora. S'utilitzava per al tractament de les pedres en el ronyó. Aquest nom no el documentem ni al DRAE ni tampoc al DIEC2 ni al DCVB. En aquest cas, el text castellà copia la forma portuguesa milsana (28) (filha a milsana i moea i dalhe a menjar o põ della nas carns, i es naõ puderes aver a milsana pren a outra), que en castellà apareix de la mateixa manera (toma la milsana e en el fin del libro fallarás que yerva es, e muélela e dale el polvo d'ella en la carne [Cap. XXII]), i que, més tard, el català converteix en 'mielsana' (66r9). El copista català desconeix aquest mot, i per això vol cercar un altre d'alternatiu, cosa que no aconsegueix, ja que deixa un espai reservat en blanc. En el text portugués trobem el terme milsana 'prenlla gradiflora', el castellà reprodueix milsana 'consuelda', 'consólida', i el català, mielsana 'herba de la mel' o 'prunella de muntanya'. En aquest cas, segurament la paraula milsana prové d'alguna denominació popular de la planta.

mill gruer. La mill gruer és una planta borraginàcia de l'espècie Lithospermum officinale, i també de la Lithospermum purpureo-caeruleum, de fulles lanceolades, flors blanques i grans petits, blancs, lluents i 
Antoni Mas i Miralles. El lèxic botànic en el Libre de Caça i els termes corresponents en altres tractats romànics

duríssims. En català s'anomena també mill gruer (66r-13) i diuen que és cria a llocs molt ombrívols, on no hi toca mai el sol. El mot prové del llatí mílium (DECat s.v. mill).

mirra. Aquesta coneguda planta, Commiphora myrrha, apareix escrita de la mateixa forma en tots els textos; és la mirra (58) en portugués, mirra (c.XXXIII) en castellà, mirra (30r-31, 34r-3) també en català i mirra en italià. Es tracta del nom de l'espècie, que recullen totes les obres, a excepció del francés. Pres del llatí MYrRHA i que, alhora, procedeix del grec $\mu$ v́ṕ $\alpha$ (DCB, s.v. mirra).

morritort. Planta crucífera de l'espècie Lepidium sativum, també coneguda amb el nom de Rorippa nasturtium-aquaticum. L'ungüent que elaboraven els falconers per a guarir tota classe de ferides contenia les fulles d'aquesta planta. En el text castellà tenim el terme mastuerço (c.XXVIII) 'mastuerzo', 'berro'; en el català morritort (61v-12, 62r-22, 62v-21, etc.) 'creixen', mentre que en el text italià registrem les variants de nasturço, nastuergo i masturzo 'crescione'. Sembla ser que les variants de mastuerço, nasturço i masturzo provenen del nom de l'espècie (del llatí medieval NASTURTIUM), en canvi l'etimologia de morritort del català no està clara, ja que sembla un derivat de morro, segons defensa Coromines (DECat, s.v. morro).

murta. És la Myrtus communi. La pols de la murta s'utilitzava per al tractament dels hematomes. A partir del nom del gènere es deriva la forma murta $(61 \mathrm{v}-12,62 \mathrm{r}-22,62 \mathrm{v}-21$, etc.) que reconeixem en el text català, mot que prové del llatí MURTA (DECat s.v. murta).

nou moscada. Correspon a la Myristica fragrans. Aquesta espècia culinària era molt apreciada per a les fórmules terapèutiques medievals. La trobem en tots els textos excepte en el francès. Així en portuguès tenim noz noscada (58), en el text castellà veiem nuez. moscada (c.XXXIII), en català nou moscada (34r-2) i en italià nuce muscata. El terme popular nou, derivat del llatí NUX (DECat s.v. nou), i fruit de la mirística, ha servit per a donar nom a aquesta espècia juntament amb la paraula moscada.

oroval. És la planta Withania somnifera, de fulles radicals, calze en forma de baldufa, corol la acampanada, és molt semblant a la belladona. Per les seues qualitats terapèutiques, aquesta planta es relaciona amb la saluvia sclarea (Hipericum androsaemum). El tractat català arreplega el terme oroval (90r29, 90r-32) 'orval', segurament un nom comú, i pròxim al francès orvale (DECat, s.v. orval).

pebre. Correspon a la Piper nigrum. El nom d'aquesta coneguda espècia apareix en el text castellà com a pimienta (c.IX) i pebre (15r-22, 15r-25, 15r-28, etc.) en el català, varietats totes dues formades a partir del gènere, mot que deriva del llatí PǏPER (DECat s.v. pebre).

pegunta. És la Pinus pinaster Aiton. Amb el residu que restava després de destil lar la trementina s'obtenia aquesta resina, anomenada pez luciente (c.XXVIII) 'pez', 'peguera' en el text castellà; pegunta (72v-29) 'colofònia' en el català, i pece grega en l'italià. Els tres termes estan relacionats amb la forma llatina PIX (DA, s.v. pes).

pimpinella. Planta rosàcia que correspon a la Poterium muricatum i també a la Sanguisorba officinalis. Per les seues propietats formava part de molts emplastres per a guarir tot tipus de trencaments. Les 
Antoni Mas i Miralles. El lèxic botànic en el Libre de Caça i els termes corresponents en altres

tractats romànics

llengües ibèriques segueixen l'etimologia de la forma llatina PENTINELLA, d'origen desconegut (DCVB s.v. pimpinella), a partir de la qual el text portugués reprodueix pipulella (63) 'pipulela', 'sanguisorba', pimpinela (c.XXX) 'pimpinela' en castellà i pimpinela (49v-29, 72v-31) 'pimpinella' en català. Els textos castellà i català ens revaliden l'equivalència de les dues formes, el primer diu: "toma una yerva que llaman pinpinela, otros la llaman bursa pastoris, otros la llaman yerva de golondrina" (Cap. XXX]) i el tractat català comenta "pinpinella, en altra manera apellada burcalastorit" (49v-30). En canvi, aquesta segona denominació correspon a la que actualment classifiquem com a Sanguisorba minor. No descartem la possibilitat que en l'època medieval les dues plantes es confongueren, ja que tenien propietats terapèutiques idèntiques. Vegeu burlacastòlit.

riubarb. Rizoma de plantes poligonàcies de diverses espècies del gènere Rheu barbărum, molt usat en l'edat mitjana com a medicament i com a aliment. A partir del nom del gènere i de l'espècie, de forma aglutinada, ha generat el terme reubarbre (63r-24, 63v-9, 63v-24, etc.) 'ruibarbre' en el text català i reubarbaro en l'italià. El mot té etimologia llatina RHEU BARBARUM, a partir d'una forma greca.

romer. Amb la cendra del romer, Rosmarinus officialis, es curava el mal dels porrets. Només apareix al text català $(41 \mathrm{v}-5)$. El nom prové, segons el DCVB, probablement d'una forma de llatina * ROMARIU, deformació de ros maris, (DCVB, s.v. romer).

rosa. Es traca de la planta de les diferents espècies del gènere Rosa. La infusió amb aquesta planta servia per a guarir el mal de pedra dels animals. Tenim rosa en català (48v-35, 48r-17), en francès rose i en italià, rosa marina. Procedeix del llatí RosarIu (DCVB s.v. rosa).

safrà. Tots els textos arrepleguen el nom d'aquesta planta, Crocus sativus, bastant coneguda i d'ús comú fins i tot en les receptes culinàries. En el text portugués tenim açafrão (4), çafrán (c.XX) 'safrà' en el castellà, safrà (16r-31, 76v-34) en el català, en el text francés arrepleguem saffrenc 'safran' i, finalment, zaferana 'zafferano' en el italiano. No cal dir que el terme utilitzat per totes les llengües procedeix de l'àrab safaran (DECat s.v. safra).

sàlser. En aquest cas es tracta d'un arbre de la família de les salicàcies, de l'espècie Salix alba. Igual que l'àlber, les branques d'aquest arbre servien per a fer barres on situar els animals. Només registrem aquest nom al text català (6r-28), i que prové del llatí salíce (DCVB s.v. sàlzerr).

sargatona (zargatona). Planta ginàcia de diferents espècies del gènere Plantago afra; s'anomena també herba pucera, pel color negre i la petitesa de les llavors. Possiblement el mot el còpia de l'obra de López d'Ayala (e la pez e azargatona e la simente de la yerva menudilla que llaman suelda menor e simiente de mastuerço e suelda rata, e de la mumia sea la mayor parte, e de suelda menudilla la cuarta parte [Cap. XXVIII]). Per al nom d'aquesta planta, les llengües romàniques ibèriques segueixen l'etimologia àrab de zarqatona (DCVB s.v. zaragatona), a partir de la qual obtenim zargatoa (15) 'zaragatoa' en portuguès, azargatona (c.XXII) 'zargatona' en castellà, o la paraula zargatona (66r-5, 66v-8, 66v-11, etc.) 'saragatona' que trobem en català. En canvi, el text italià reprodueix psylio minut, que és la referència que utilitza Dioscòrides per a aquest tipus de plantes medicinals (Gil 1999: 118). 
Antoni Mas i Miralles. El lèxic botànic en el Libre de Caça i els termes corresponents en altres

tractats romànics

segó. El segó, la pell de diversos cereals, era un dels ingredients en què es feia un emplastre per a 'lo mal de les exuagues'. Només el trobem al text català (91v-23). El DCVB proposa la procedència llatina de SECUNDUM (s.v. segô).

siexnerga. Desconeixem a quina espècie d'herba es refereix. En aquesta ocasió el text català reprodueix la forma ben pròxima a la del portuguès seuxevegra (28) que escriu Menino (filha a milsana i moea, i dalhe a menjar o pó della nas carns, $i$ es não puderes aver a milsana pren a seuxevegra). Sembla que, igual que en altres ocasions, el text català copia (e si d'esta erba no podets haver, hajats siexnerga, en altra manera apellada [espai en blanc] e fets-ne pólvora com dit és (66r10), sense trobar cap alternativa genuïna.

sucre candi. És la planta Saccharum officinarum, que apareix en multitud de fórmules terapèutiques en què era un ingredient bàsic. Per açò els textos arrepleguen les variants següents: açúcar (4) 'açúcar cresol' en portuguès, açúcar blanco (c.XXXIII) 'azúcar candi' en castellà, el sucre candi (65r-23, 65r-25, 66v-26, etc.) en català i zuccaro candio en italià. Com podem deduir, el terme prové de la forma àrab súkekar (DECat, s.v. sucre).

sueldaraca. La Centaurea solstitialis és una mena de 'consolda raca', però sembla que el copista català no detecta que és tracta de dues paraules i per això opta per copiar el mateix mot que troba al text castellà (toman la mumia que tienen els boticarios y espeçieros [...] y suelda raca [Cap. XXVIII]). En altres ocasions, quan troba el mot 'suelda', el copista el tradueix automàticament com a 'consolda'. (Vegeu 'consolda'). No obstant això, en aquest cas el copista intenta cercar una altra alternativa, 'arzolla', tot i que és tracta d'un altre castellanisme (preneu tanta mumia com una avellana, $\mathrm{i}[. .$.$] i sueldaraca, en altra manera apellada arzolla (72v-32). Aquesta planta la identifiquem$ en el text portugués com a soldaraca (47) 'solda', en el castellà tenim suelda de rata (c.XLVII) i en català sueldaraca $(72 \mathrm{v}-32)$, possiblement perquè, com ja hem apuntat al principi, la tradició de copiar d'unes obres a unes altres funcionava.

sumach. Planta terebintàcia, Rhus coriaria, que és fa de dos a tres metres d'alçada. Planta utilitzada en les diferents fórmules que servien per a desinflamar qualsevol part del cos del falcó. Apareix també en el mateix context amb la forma castellana (toma el aziche e la casca de la enzina e la escoria e el çumaque, tanto de lo uno como de lo otro [Cap. XXVI]) que en l'obra catalana (quant veurets que serà ja ben curat $\mathrm{i}$ guarit $\mathrm{i}$ ben cuyrat, preneu oli, i tany, i cagaferro i sumach 36v1). L'ètim àrab summaq (DCVB s.v. sumac) ha proporcionat a les llengües romàniques els termes següents: sumagre (40) en portuguès, çumaque 'zumaque' en castellà, sumach 'sumac' en català, sumac en francés i çumaque 'sommacco' en italià. Com observem, les diferents denominacions provenen de l'àrab summâq (DECat s.v. sumac), sense tenir en compte el nom científic de la planta, ja que segurament té un arrel popular.

trementina. En aquest cas no tenim la seguretat de si es refereix a la Pistacia terebinthus o es tracta de la resina obtinguda del Pinus pinaster Aiton. S'utilitzava en el tractament de determinades ferides. 
Antoni Mas i Miralles. El lèxic botànic en el Libre de Caça i els termes corresponents en altres

tractats romànics

Del nom de l'espècie terebinthus, que prové del llatí, a partir del mot tereBInTHus, i aquest d'una altra forma grega (DECat s.v. terebint), se'n deriva la forma trementina (37) que anotem en portugués i en castellà (c.XLVI) 'cornicabra', 'terebinto'; en catalán trementina (40r-10) 'noguerola', 'teberint', i també trementina en italià 'terebinto'.

turbit. Planta convolvulàcia, de l'espècie Ipomoea turpethum, que té propietats purgants. En altres classificacions li assignen el nom científic de Thapsia villosa. En aquest cas, el nom de l'espècie és la responsable del terme turbit, que trobem en els textos català $(17 \mathrm{r}-9,60 \mathrm{v}-15)$ i italià. El mot té etimologia àrab (DCVB s.v. turbit).

verdet. Molsa, o pot ser fa referència a la planta de l'espècie Antirrbinum majus. S'utilitzava per a curar porrets i claus que es feien els ocells en les potes. Només ho trobem en el text català, verdet (40v31, 91v-22, 92), i segurament també en el text castellà, on registrem verdetis, quan diu "Cardenillo, otros lo llaman verdetis." (c.XLVII). Exactament, Coromines recull que el verdet és conegut també en valencià com el 'cardenillo' (DECat s.v. verd). El mot, a més, prové del llatí.

\section{Conclusions}

Les obres de falconeria medieval proporcionen un vast conjunt de termes botànics, i a més ens ajuden a conèixer l'evolució etimològica de mots del registre científic. En el nostre inventari tenim un total de 174 mots, dels quals 63 provenen del tractat català el Libre de Caça, a partir del qual hem buscat també en les altres obres, 36 de l'obra castellana, 28 de la portuguesa, 12 de la francesa i, finalment, 35 del tractat italià (Vegeu l'annex).

Com hem comprovat al llarg del treball, la majoria dels noms deriven de la denominació del gènere, de l'espècie o d'una forma aglutinada de les dues, però en altres casos emanen d'ètims populars. En aquest sentit, cal tenir en compte, d'una banda, que les plantes més conegudes són les que més variants presenten, resultat de la variació de les formes populars, i, d'altra banda, que els noms binomials són creats posteriorment, concretament al segle XVIII pel científic C. Linnaeus, i per tant són noms compostos, moltes vegades, a partir de l'etimologia popular.

A partir de l'inventari de plantes realitzat, proposem la següent classificació:

a) Noms que són compartits pels cinc tractats. Són les plantes més conegudes i de major ús en les obres de farmacologia medieval. En aquest grup registrem les deu plantes següents: almàstec, alosna, canella, caparaz o estrafisagria, consolda, ensens, fenoll, girofle, safrà, sèver i sumach,

b) Grup ibero-romànic. Cal dir, en primer lloc, que observem com les llengües peninsulars 
seran les receptores de la majoria d'ètims procedents de l'àrab. El lexicògraf Lüdtke(1974: 82), quan comenta la influència del lèxic àrab en la Romania, distingeix clarament quatre vies de penetració, i la primera la situa en la península Ibèrica com a conseqüència del poder que va sostenir l'islam al llarg de huit segles de contacte lingüístic. En aquest grup trobem les set plantes següents: aixonca, herba cuquera, mielsana, pebre, pimpinella, sueldaraca i aryolla,

c) Grup català i italià. Si la veritat és que el català l'incloíem en el grup iberoromànic, mentre que el francès i l'italià els deixàvem fora, també hem de ressaltar que el català és la llengua menys ibero-romànica de les tres i, per contra, l'italià, a diferència del francès, la més pròxima a les ibero-romàniques. Possiblement aquestes característiques han propiciat la convergència d'aquestes dues llengües, sense descartar tampoc la influència que podia tenir la procedència de l'autor valencià en l'obra redactada en italià. Aquestes dues llengües comparteixen vuit d'aquests termes: camamirla, giripriga, hermotatil, jemgibre, limó, llentiscle, reubarbe, sèver sucotrí, turbit i verdet.

d) Grup tots menys francés. Segurament, com a conseqüència del que hem exposat en el punt anterior, el francès apareix com una llengua diferent a la resta del grup, la qual cosa possibilita que totes compartesquen aquest vocabulari. En total són tretze termes: almàstec, burcalastorit, cataprusa, falsia, menudina, mirra, morritort, nou moscada, pegunta, sucre candi, trementina i zargatona.

e) Exclusives en català. En aquest últim grup, donem a conèixer el vocabulari exclusiu que solament registrem en aquesta llengua: àlber, alfals, alquena, api, fetge, genciana, junch, manrubio, mill gruer, murta, oroval, romer i sàlser.

f) Altres. Com a complement dels punts anteriors, tenim altres plantes amb una agrupació diferent de les exposades fins ara. Hi anotem el julivert, que apareix també en castellà i en francès, mentre que el donzell i el crespinell que es reprodueixen en francès $i$ en italià, $i$, en tercer lloc, apuntem la pegunta i la falsia que també les tenim en les obres castellana i italiana.

Finalment, podem assenyalar que l'anàlisi del nostre inventari ens ha servit també per a conèixer, d'una banda, la influència que sobre les llengües romàniques estudiades exercien les etimologies del llatí i de l'àrab. La gran majoria són termes que procedeixen del llatí, i alhora derivats d'un altre terme grec, com és el cas de (canyafístula, giripriga, margarita, trementina, etc.). El segon grup està constituït pels mots que provenen de l'àrab (alosna, arzolla, safrà, caparaz, alquena, alfals, zargatona, sumach, sucre, etc.). En tercer lloc, hem d'anotar que els mots que deriven d'una etimologia popular provenen, majoritàriament, d'ètims llatins (canela, crespinell, espic, exonca, falsia, fetge, fenoll, segó, herba cuquera, pebre, etc.). 
Antoni Mas i Miralles. El lèxic botànic en el Libre de Caça i els termes corresponents en altres tractats romànics

\section{Bibliografia}

Archivo Iberoamericano de cetrería, http://www.aic.uva.es/index.html.

Cifuentes, L. (2006) La ciència en català a l'Edat Mitjana i el Renaixement, Barcelona, Publicacions i Edicions de la Universitat de Barcelona, col. «Blaquerna» 3, (1 a ed. 2002).

DA: Corpus del Nuevo Diccionario Histórico. http://web.frl.es/DA.html.

DCVB: Alcover, A. - Moll, F. (1930-19629) Diccionari Català-Valencià-Balear, Ciutat de Mallorca, Moll, 10 vols., http://dcrb.iec.cat/.

DECat: Coromines, J. (1980-1990) Diccionari Etimologic i Complementari de la Llengua Catalana, 9 vols., Barcelona, Curial.

Delgado, M. (2006) Edición crítica del «Libro de la caza de las aves» de Pero López de Ayala, Madrid, Ediciones Calasancias.

DI: Dizionario italiano, http://www.dizionario-italiano.it/.

DIEC: Diccionari de la Llengua Catalana de l'IEC, http://DIEC.iec.cat/.

DPLP: Dicionário Priberam da Língua Portuguesa, http://www.priberam.pt/dlpo/.

DRAE: Diccionario de la Lengua Española, http://buscon.rae.es/drae.

Ferragud, C. (2011) "La atención médica de los animales en la baja Edad Media en los reinos Hispánicos", Medievalismo 21, p. 29-54.

Flora Catalana, http://www.floracatalana.net/.

García, M. et al. (20013) El Libre de caça, un tractat medieval de falconeria, Barcelona: Institut Interuniversitari de Filologia Valenciana - Publicacions de l'Abadia de Montserrat, «Biblioteca Sánchis Guarner», 2013.

Gil, T. (1999) "El léxico de la botánica en el Vocabulario de Cristóbal de las Casas", Cuadernos de Filología Italiana, núm. 6, p. 117-140.

Lagae É. (2005) “Un traité inédit d'autourserie et de fauconnerie en moyen français", Anthropozoologica 40 (2), p.81-99.

Lüedtke, H. (1974) Historia del léxico románico. Madrid, Editorial Gredos.

Olmos, R. (2013) "Medicina animal en la baja Edad Media Hispánica y su relación con la medicina humana: aves, perros y caballos", Anuario de Estudios Medievales, p. 199-242.

Rodrigues, M. (ed.) (1931) Livro de Falcoaria de Pero Menino, Publicado com introdução, notas e glossário por Rodrigues Lapa, Coimbra: Impremsa de Universidade, Junta de educação, Nacional, Centro de estudios filológicos. 
Antoni Mas i Miralles. El lèxic botànic en el Libre de Caça i els termes corresponents en altres tractats romànics

Santoyo, J. (2004) "La Edad Media", Francisco Lafarga y Pegenaute (eds.), Historia de la Traducción en España (ed.), Ambos Mundos, Salamanca, p. 23-174.

Sciencia.cat, http://www.sciencia.cat/biblioteca/catalegdobres.htm.

Vallés, J. et ali. (2009): Noms de les plantes, Termcat. http://www.termcat.cat/docs/DL/noms plantes $/$.

Van den Abeele, B. (1994) La Fauconnerie a moyen age: connaissance, affaitage et medicine des oiseaux de chasse d'aprés les traités latins, París, Klincksieck.

Wittlin, C. (1998) "La biblioteca de la familia Mercader de València l'any 1489", Caplletra-24, p. 93104.

SCRIPTA, Revista internacional de literatura i cultura medieval i moderna, núm. 12/ desembre 2018/pp. 198-219 ISSN: 2340 - 4841 doi:10.7203/SCRIPTA.12.13393 
Antoni Mas i Miralles. El lèxic botànic en el Libre de Caça i els termes corresponents en altres tractats romànics

Annex

\begin{tabular}{|c|c|c|c|c|c|}
\hline NOM CIENTÍFIC & CATALÀ & CASTELLÀ & PORTUGUÉS & FRANCÉS & ITALIÀ \\
\hline Aloe vera & Sèver & Acíbar & Acevar & aloue epatif & acevar \\
\hline Populus alba & àlber & - & - & - & - \\
\hline Medicago sativa & Alfalç & - & - & - & - \\
\hline Chondrilla juncea & $\begin{array}{l}\text { almàstec } \\
\text { màstec }\end{array}$ & almástiga & $\begin{array}{l}\text { almacega } \\
\text { mastiz }\end{array}$ & - & $\begin{array}{l}\text { mastice } \\
\text { almecega }\end{array}$ \\
\hline Artemisia absintbium & $\frac{\text { alosna }}{\text { donzell }}$ & $\frac{\text { Alosna }}{\text { ansenxo }}$ & Alosna & aloine & $\frac{\text { alosna }}{\text { assencio }}$ \\
\hline Artemisia arborescens & donzell & doncel & codesso & armoise & \\
\hline Lawsonia inermes & alquena & - & & - & - \\
\hline Apium graveolens & Api & - & - & - & - \\
\hline Centaurea solstitialis & $\begin{array}{l}\text { Sueldaraca } \\
\text { arzolla }\end{array}$ & suelda de rata & soldaraca & - & Th \\
\hline Capsella bursa-pastoris. & Burcalastorit & bursa pastoris & - & - & virga pastoris \\
\hline Sanguisorba minor & pimpinela & $\begin{array}{l}\text { pimpinela } \\
\text { yerva de } \\
\text { golondrina }\end{array}$ & pipulella & - & - \\
\hline Euphorbia lathyris & cataprusa & tártago & Tartego & cataponya & - \\
\hline Matricaria Chamomilla & camamirla & - & - & - & camomilla \\
\hline Cinnamomum verum & canella & Canela & Canela & synamon & cannèlla \\
\hline Casiae fistüla & canyafístola & - & & - & - \\
\hline Delphinium staphisagria & $\begin{array}{l}\text { Caparaz } \\
\text { fabaraz }\end{array}$ & fabarraz & paparaz & estafizacre & strafisagria \\
\hline Sysygium aromaticum & claus de girofle & clavos de girofle & $\begin{array}{l}\text { cravos } \\
\text { girofos }\end{array}$ & $\begin{array}{l}\text { cloux de } \\
\text { giroflé }\end{array}$ & gariofali \\
\hline Symphytum officinale & consolda & Suelda & Solda & consoude & consolida \\
\hline Sedum acre & herba d'onzell & - & - & - & - \\
\hline Boswellia sacra Flueckiger & ensens & ençienso & incensso & encens & incènso \\
\hline Lavandula latifolia & espic & $\begin{array}{l}\text { espic } \\
\text { espique }\end{array}$ & espique & - & spica \\
\hline Conium maculatum & eixonca & eixonca & Cixuta & - & - \\
\hline $\begin{array}{l}\text { Adiantbum capillus- } \\
\text { Veneris }\end{array}$ & falsia & culantro & - & - & cogliandro \\
\hline Foeniculum vulgare & finojo & Finojo & Funcho & fenoul & fenochio \\
\hline Hepatica nobilis & fetge & - & - & - & - \\
\hline
\end{tabular}

SCRIPTA, Revista internacional de literatura i cultura medieval i moderna, núm. 12/ desembre 2018/pp. 198-219 ISSN: 2340 - 4841 doi:10.7203/SCRIPTA.12.13393 
Antoni Mas i Miralles. El lèxic botànic en el Libre de Caça i els termes corresponents en altres tractats romànics

\begin{tabular}{|c|c|c|c|c|c|}
\hline Gentiana lutea & genciana & - & - & - & - \\
\hline Zingiber officinale & jengibre & - & - & - & zinzivero \\
\hline Aloe perryi & $\begin{array}{l}\text { sèver sucotrí } \\
\text { giripriga }\end{array}$ & & & & gerapriga \\
\hline $\begin{array}{l}\text { Lithospermum purpureo- } \\
\text { caeruleum } \\
\text { Lithospermum officinale }\end{array}$ & mill gruer & - & - & - & - \\
\hline $\begin{array}{l}\text { Santolina } \\
\text { chamaecyparissus }\end{array}$ & herba cuquera & $\begin{array}{l}\text { yerba } \\
\text { lombriguera }\end{array}$ & erva lonbriugeira & - & - \\
\hline Colchicum autumnale & hermotàtil & - & - & - & ermodattoli \\
\hline Petroselinum crispum & jolivert & Perexil & - & persin & - \\
\hline $\begin{array}{l}\text { Juncus communis } \\
\text { Iuncus effusus }\end{array}$ & Junch boval & - & - & - & - \\
\hline Pistacia lentīscus & llentiscle & - & - & - & lentisco \\
\hline Citrus limonum & limó & - & - & - & limoncelo \\
\hline Marrubium vulgare & manrubio & - & - & - & - \\
\hline Cytinus bypocistis & margarita & - & - & - & - \\
\hline $\begin{array}{l}\text { Artemisia camphorata } \\
\text { Vill. }\end{array}$ & menudina & Menudilla & Maminha & - & herba minuta \\
\hline Prunella grandiflora & mielsana & Milsana & Milsana & - & - \\
\hline Commiphora myrrba & mirra & Mirra & Mirra & - & mirra \\
\hline $\begin{array}{l}\text { Lepidium sativum } \\
\text { Rorippa nasturtium- } \\
\text { aquaticum }\end{array}$ & morritort & Mastuerço & - & - & $\begin{array}{l}\text { nasturço, } \\
\text { nastuergo i } \\
\text { masturzo } \\
\end{array}$ \\
\hline Myrtus communis & murta & - & - & - & - \\
\hline Myristica fragrans & nou moscada & nuez moscada & noz noscada & - & nuce muscata \\
\hline Withania somnifera & oroval & - & - & & - \\
\hline Piper nigrum & pebre & Pimienta & - & - & - \\
\hline Pinus pinaster Aiton & pegunta & pez luciente & - & - & pece grega \\
\hline $\begin{array}{l}\text { Poterium muricatum } \\
\text { Sanguisorkg officinalis }\end{array}$ & pimpinela & Pinpinela & Pipulella & - & $20 \mathrm{r}-\mathrm{b}$ \\
\hline Rheu barbarum. & reubarbre & - & - & - & reubarbaro \\
\hline Rosmarinus officialis & romer & - & - & - & - \\
\hline Rosa & Rosa & - & - & - & - \\
\hline Crocus sativus & safrà & Çafran & Açafrão & saffrenc & zaferana \\
\hline Salix alba & sălser & - & - & - & - \\
\hline Plantago afra & zargatona & Azargatona & Zargatoa & - & psylio minut \\
\hline
\end{tabular}


Antoni Mas i Miralles. El lèxic botànic en el Libre de Caça i els termes corresponents en altres tractats romànics

\begin{tabular}{|l|l|l|l|l|l|}
\hline Saccharum officinarum & sucre candi & açúcar blanco & Açúcar & - & zuccaro candio \\
\hline Rhus coriaria & sumach & Çumaque & Sumagre & - & çumaque \\
\hline Pistacia terebinthus & trementina & trementina & trementina & & trementina \\
\hline Ipomoea turpethum & turbit & - & - & - & turbit \\
\hline Antirrbinum majus & verdet & verdetis & - & - & - \\
\hline
\end{tabular}

SCRIPTA, Revista internacional de literatura i cultura medieval i moderna, núm. 12/ desembre 2018/pp. 198-219 ISSN: 2340 - 4841 doi:10.7203/SCRIPTA.12.13393 